\section{REFLEXÕES SOBRE O ENSINO DE MATEMÁTICA A PARTIR DA RELAÇÃO ENTRE A ETNOMATEMÁTICA E A EDUCAÇÃO AMBIENTAL CRÍTICA}

\author{
Rodrigo Bozi Ferrete - IFS \\ Anne Alilma Silva Souza Ferrete - UFS \\ Cassio Magno de Sousa - IFS
}

\section{Resumo}

O presente estudo teve como objetivo analisar a prática do ensino de Matemática do curso Técnico Integrado em Edificações do Instituto Federal de Sergipe (IFS), a partir da relação entre a Etnomatemática e a Educação Ambiental Crítica. Para isso, foi realizada uma pesquisa de cunho qualitativo, desenvolvida através de intervenção na disciplina de Matemática II, do Curso Integrado em Edificações em que atividades de ensino do conteúdo da Matemática, foram elaboradas pautadas nas concepções teóricas da Etnomatemática e da Educação Ambiental Crítica. Os resultados indicam o entendimento mais complexo da importância e do significado da Matemática; motivação para participar e assistir às aulas de Matemática; interesse em continuar pesquisando mais informações sobre os problemas abordados nas aulas; aumento da autoestima relacionada à capacidade e ao conhecimento que possuem; desenvolvimento do pensamento crítico para entender os problemas de seu cotidiano; responsabilidade e desenvolvimento da autonomia enquanto cidadãos ativos da sociedade.

Palavras-chave: Educação Ambiental Crítica. Educação Matemática. Etnomatemática.

\section{REFLECTIONS ON THE TEACHING OF MATHEMATICS FROM THE RELATION BETWEEN ETHNOMATHEMATICS AND CRITICAL ENVIRONMENTAL EDUCATION}

Keywords: Critical Environmental Education. Ethnomathematics. Mathematical Education. 


\section{REFLECTIONS EN LA ENSEÑANZA DE LAS MATEMÁTICAS DE LA RELACIÓN ENTRE ETHNOMATHEMATICS Y CRITICAL ENVIRONMENTAL EDUCATION}

\section{Resumen}

El presente estudio tuvo como objetivo analizar la práctica de la enseñanza de Matemáticas del curso Técnico Integrado en Edificaciones del Instituto Federal de Sergipe (IFS), a partir de la relación entre la Etnomatemática y la Educación Ambiental Crítica. Para ello, se realizó una investigación de cuño cualitativo, desarrollada a través de intervención en la disciplina de Matemática II, del Curso Integrado en Edificaciones en que actividades de enseñanza del contenido de la Matemática, fueron elaboradas pautadas en las concepciones teóricas de la Etnomatemática y de la Educación Ambiental Crítica. Los resultados indican el entendimiento más complejo de la importancia y el significado de las matemáticas; motivación para participar y asistir a las clases de Matemáticas; interés en continuar investigando más información sobre los problemas abordados en las clases; aumento de la autoestima relacionada con la capacidad y el conocimiento que poseen; desarrollo del pensamiento crítico para entender los problemas de su cotidiano; responsabilidad y desarrollo de la autonomía como ciudadanos activos de la sociedad.

Palabras clave: Educación Ambiental Crítica. Educación Matemática. Etnomatemáticas.

\section{Introdução}

Ao revisarmos trabalhos de Etnomatemática publicados observamos que estes buscavam investigar o conhecimento etnomatemático de determinada cultura, sem levar em consideração o ambiente de produção desses conhecimentos. E também pela escassez de pesquisas práticas sobre essa temática relacionada ao ensino da Matemática em escolas urbanas. Essas constatações suscitou a necessidade de investigarmos as possibilidades metodológicas para relacionar a Etnomatemática e a Educação Ambiental Crítica no ensino da Matemática.

Araujo (2004) destaca que as questões sociais e ambientais não podem ser trabalhadas apenas como um elemento ilustrativo nas aulas, mas devem ser abordadas como parte inerente à educação do indivíduo. Nesta perspectiva, temas como o consumo de energia elétrica, a produção de lixo, a reciclagem, o desmatamento, a poluição do ar, o consumo de água, entre tantas outras temáticas, podem ser abordados nas aulas de Matemática, mas levando-se em consideração a relação desses temas com o cotidiano dos estudantes.

Nessa perspectiva, e para viabilizar a pesquisa, optamos por trabalhar no segundo ano do Curso Técnico Integrado em Edificações do Instituto Federal de Sergipe (IFS). E com o intuito de contribuir com a discussão relativa ao ensino da Matemática, a Etnomatemática e a Educação Ambiental desenvolvemos esse trabalho com o objetivo geral de analisar a prática do ensino de Matemática do curso Técnico Integrado em Edificações a partir da relação entre a Etnomatemática e a Educação Ambiental Crítica.

\section{Metodologia da Pesquisa}

Por identificarmos nas propostas pedagógicas da Etnomatemática, na concepção de D'Ambrosio (2001), e da Educação Ambiental Crítica, na concepção de Araujo (2004), a influência de Paulo Freire $(1967 ; 1994)$, entendemos que elas podem ser trabalhadas juntas. Mas como fazer isso? Para responder a esse problema de pesquisa realizamos uma investigação com o $2^{\circ}$ ano do curso Técnico Integrado em Edificação do IFS, a fim de viabilizarmos o desenvolvimento dessa 
metodologia no ensino de Matemática. Enquanto preocupação instrumental, desenvolvemos uma investigação de abordagem qualitativa que segundo Richardson (1999, p. 90),

\begin{abstract}
[...] pode ser caracterizada como a tentativa de uma compreensão detalhada dos significados e características situacionais apresentadas pelos entrevistados, em lugar da produção de medidas quantitativas de características ou comportamento.
\end{abstract}

Optamos por trabalhar com uma pesquisa qualitativa por partimos da prerrogativa de não ficarmos prisioneiros a números, estatística, quantidades de ocorrências, e sim, de buscarmos dados não quantificáveis que qualifique, considere, caracterize, ou mesmo conceitue, os dados levantados na pesquisa. Para isso, buscamos dados para: construir a perspectiva da realidade dos alunos do $2^{\circ}$ ano desse curso; entender como os alunos e professores do $2^{\circ}$ ano compreendem a Educação Ambiental; mapear os problemas ambientais que eles vivenciam; identificar o que é trabalhado de Educação Ambiental no $2^{\circ}$ ano do curso; investigar quais conhecimentos etnomatemáticos os alunos do $2^{\circ}$ ano possuem; entender como a disciplina de Matemática é ensinada no $2^{\circ}$ ano; verificar qual a importância dessa disciplina para o curso; e investigar o que os alunos do $2^{\circ}$ ano compreendem por Matemática.

Os dados foram levantados a partir das observações realizadas em sala de aula; aplicação de questionário composto por perguntas abertas e fechadas, aplicado aos alunos do $2^{\circ}$ ano; entrevistas semiestruturadas realizadas com oito professores, destes, quatro de Matemática que ensinam ou ensinaram no curso, e quatro de disciplinas da área técnica do curso.

Analisamos, ainda, os documentos do IFS como: o Projeto Pedagógico do Curso Integrado em Edificações; o Plano de Desenvolvimento Institucional (PDI); as ementas das disciplinas do Curso Integrado em Edificações; os planos de ensino; os planos de aula do referido curso; a Regulamentação da Organização Didática do IFS (ROD); a Regulamentação de Encargos Docentes do IFS (RED); a revisão geral da legislação sobre as obrigações legais do IFS, a oferta dos cursos técnicos e sobre o ensino de Matemática.

As atividades de ensino foram estruturadas metodologicamente da seguinte forma:

- um assunto que indica o conteúdo matemático geral abordado;

- um título que indica o tema central da Matemática a ser investigado na aula;

- um conteúdo que descreve tanto o conhecimento matemático a ser trabalhado, como o conhecimento da Educação Ambiental e da Etnomatemática, sendo destacados separadamente.

O conteúdo da Educação Ambiental escolhido para cada aula foi determinado pela perspectiva de relação com o conteúdo matemático a ser trabalhado na aula e também pela relação do tema com a área de edificações, por constatarmos que os estudantes fazem o curso por gostar e se identificar com essa área. Outro fator importante para a escolha do tema foi a relevância deste no cotidiano dos discentes, por identificarmos, no período de observação e nos questionários, uma fragilidade deles em relação a esses temas, tanto conceitual como pelo grau de importância da temática, ou ainda pela falta de opinião e atitude em relação ao tema.

Em relação ao conteúdo da Etnomatemática, este foi escolhido a partir dos conhecimentos etnomatemáticos identificados no grupo cultural dos estudantes do Curso Técnico Integrado em Edificações do IFS, tanto a partir das observações realizadas, como pelas respostas nos questionários. A partir dessas informações e após a escolha do tema da Educação Ambiental, foi possível mapearmos quais conhecimentos etnomatemáticos poderiam ser explorados dando prioridade para esses conhecimentos em detrimento de trabalhar a forma tradicional da Matemática acadêmica. Essa forma de trabalho nos permitiu aproximar as questões da Educação Ambiental à forma como os estudantes agem e pensam sobre a temática. Ou seja, possibilitou discutirmos as questões ambientais no cotidiano dos estudantes, valorizando os processos cognitivos desenvolvidos pelos mesmos, proporcionando uma maior liberdade para os estudantes se expressarem da forma que sabem, sem se preocuparem inicialmente com o caráter científico do problema. 
Somente após um debate inicial sobre o tema, levantando os conhecimentos etnomatemáticos dos estudantes sobre o mesmo, é que foi previsto a realização de uma avaliação diagnóstica oral momentânea, para decidirmos se os conhecimentos etnomatemáticos da turma eram suficientes para analisar o tema. A partir disso, prevíamos a continuidade de duas formas: i) mostrando como os conhecimentos da Matemática podem ajudar no debate sobre o tema; ii) caso o conhecimento etnomatemático dos estudantes fosse suficiente para o debate sobre o tema, seria apresentado o conteúdo matemático através de uma comparação entre o conhecimento matemático e o conhecimento etnomatemático dos discentes.

É importante destacarmos que nessa proposta metodológica não há o objetivo de substituir os conhecimentos etnomatemáticos dos estudantes pelos conhecimentos da Matemática acadêmica, e nem vice-versa. $O$ objetivo é ensinar a Matemática acadêmica a partir dos conhecimentos etnomatemáticos dos estudantes, por acreditarmos que dessa forma, é possível dar significado e sentido a esses conhecimentos, mostrando a importância deles na vida do estudante e na sociedade. As diretrizes desse momento foram norteadas pelos seguintes ingredientes:

- Objetivos - para cada encontro foi previsto as principais finalidades da realização do mesmo, sendo destacados também, os objetivos pretendidos em relação ao conteúdo da Educação Ambiental e da Etnomatemática.

- Um roteiro de ensino que descrevia de forma sucinta como cada conteúdo e objetivo podia ser desenvolvido e as possíveis formas de tentar alcançá-los, servindo como um roteiro préestabelecido para cada atividade. No final de cada atividade, era recomendado explorar exercícios do livro didático como maneira de aprofundar a habilidade dos estudantes em resolver questões. Além disso, o livro didático era utilizado como uma leitura complementar sobre o assunto que, quando possível e necessária, deveria ser realizada em sala de aula ou indicada para ser feita como atividade extraclasse.

- Uma metodologia proposta para ser utilizada durante a realização das atividades, pautada no diálogo com os estudantes e não pela imposição de regras, uma vez que a condução dessas atividades dependia diretamente da participação dos discentes durante as aulas.

A análise dos dados coletados foi realizada mediante a concepção da Análise do discurso de Orlandi (2008, p. 23), o qual explica que “(...) o objetivo da análise do discurso é descrever o funcionamento do texto. Em outras palavras, sua finalidade é explicar como um texto produz sentido." Apesar de parecer simples, pela forma como ela apresenta o objetivo da análise do discurso, essa se constitui em uma tarefa árdua e complexa, por ser um método que não busca simplesmente comparar ou enumerar os dados, mas sim, compreender como eles fazem sentido, através de interpretação subjetiva dos mesmos. Essa opção ocorreu por considerarmos que, uma análise técnica dos dados coletados, interpretando apenas o que foi dito sem um contexto, não seria o mais adequado para alcançar as respostas que procurávamos na pesquisa.

\section{Resultados e discussão}

Através das opções metodológicas escolhidas, caracteriza-se a realização de todas as aulas, de forma geral, através de quatro momentos diferentes:

\section{Aulas realizadas a partir de temas geradores de problematização}

Esse tipo de aula ocorreu com maior frequência, pois foi utilizado para o desenvolvimento de sete dos oito conteúdos matemáticos trabalhados, só não sendo utilizado para o desenvolvimento do assunto Determinantes. A metodologia proposta nessas aulas partiu sempre da discussão de um problema ambiental pertinente à área de Edificações e da realidade dos estudantes, a partir de um texto básico atual sobre o tema, cuja leitura era realizada em voz alta por um estudante que se candidatava espontaneamente para fazê-la. Após a leitura do texto, perguntávamos a opinião deles sobre esse assunto, seguindo o roteiro de ensino pré-definido para cada aula. Nas primeiras atividades realizadas, percebemos uma timidez ou preocupação dos estudantes em manifestar suas opiniões, situação rapidamente superada a partir 
da segunda e terceira aulas, quando aumentou consideravelmente o trabalho para controlar as falas dos estudantes após a leitura do texto, pois muitos deles queriam falar ao mesmo tempo.

Essas reações iniciais de timidez dos estudantes haviam sido observadas nas aulas assistidas dos outros professores, em que os estudantes só se manifestavam após o professor apresentar sua opinião. Nesses momentos observados, os estudantes se limitavam a manifestar sua opinião concordando com o ponto de vista do professor, sendo que em nenhum momento, presenciamos um estudante apresentando uma opinião contrária. Esse dado nos remete a questões trabalhadas por Freire (1994) sobre a opressão que os estudantes estão acostumados a passar. O professor sempre quer que os mesmos prestem atenção e aprendam apenas o que ele quer ensinar; concorde com ele, com seus pontos de vista, enquanto que o conhecimento dos estudantes não possui relevância, pois o que importa e tem valor é a opinião ou conceito do professor.

Destacamos que o importante após a fala do estudante, ao invés do professor fazer qualquer comentário sobre ela, foi insistirmos para os outros falassem, mostrando que o papel do professor era apenas o de mediador dos debates. Eles rapidamente entenderam isso, adaptaramse a esse novo posicionamento pedagógico e começaram a fazer questão de expressar suas opiniões sem se preocuparem com a opinião do professor.

Outro fator importante que identificamos após a leitura dos textos foi a falta de conhecimento dos estudantes sobre as questões abordadas. Apesar de terem sido escolhidas a partir de suas realidades e estarem relacionadas à área de interesse dos mesmos, os estudantes demonstraram não possuir outras leituras sobre o problema. Suas colocações se baseavam na opinião ou discurso de outras pessoas, ou mesmo em reflexões que eles formulavam logo após a leitura. Essa questão provocou constantemente troca de posicionamentos produzidos pelo efeito do ponto de vista contrário expresso por outro colega que levava o estudante a abandonar seu conceito original e a concordar com a ideia do outro. Isso evidenciou um lado positivo, por mostrar que os estudantes estão abertos a opiniões contrárias e, negativo, por expor a falta de criticidade e argumentos para defender suas opiniões.

Mudar de ponto de vista e de opinião sobre um tema é algo bom, benéfico, que evidência criticidade. No entanto, ao observarmos um estudante apresentando uma opinião, outro apresentando um argumento contrário e imediatamente ver aqueles que concordavam com a opinião inicial concordarem com a ideia contrária, evidencia fragilidade em relação aos argumentos que se aceitam como verdades, bem como a falta de conhecimento sobre o que está sendo discutido. Por isso, enquanto os estudantes apresentavam seus argumentos, o professor sintetizava as ideias principais no quadro, evidenciando os argumentos favoráveis e contrários, até que todos expressassem suas ideias e opiniões sobre o tema, não obrigando ninguém a falar. Entendemos que o papel do professor era o de indagar os estudantes sobre a validade da afirmação que os mesmos estavam fazendo e questionando os demais colegas a concordarem ou não com as afirmações feitas.

Essa metodologia de ensino com temas geradores no início das aulas provocou uma mudança de hábitos, aguçando a curiosidade dos estudantes para os problemas e questões ambientais existentes, bem como uma necessidade de buscarem mais informações e um entendimento de que os problemas existentes na sociedade necessitam ser discutidos mais profundamente para poderem ser resolvidos ou minimizados.

Em média, o procedimento de leitura e debate durou 25 minutos, sendo 5 minutos para a leitura do texto, com alguma informação complementar introduzida pelo professor, seguidos de 20 minutos de debate. Os debates eram encerrados ao observarmos que todos os argumentos já haviam sido expostos e começava a ocorrer repetição. O encerramento ocorria através da explicação que cada um deveria ter sua opinião e o máximo possível de argumentos favoráveis a ela, não existindo verdade absoluta, apenas pontos de vista diferentes que deviam ser respeitados.

Nos últimos 60 minutos de aula realizávamos a leitura coletiva do assunto no livro didático, sistematizando-se todo o conhecimento discutido em sala de aula, fazendo algumas observações 
complementares quando pertinentes e, por fim, resolvendo questões propostas no livro, indicando outras para serem resolvidas em casa como atividade complementar.

\section{Aulas realizadas a partir da manipulação de material concreto}

Para desenvolvermos o conteúdo de Geometria espacial, além da utilização de temas geradores de problematização, discutindo a questão do lixo urbano, realizamos uma oficina na própria sala de aula, reutilizando alguns materiais previamente solicitados aos estudantes: latas de milho, de ervilha, de leite condensado (abertas, utilizadas e lavadas); caixas de sapato, e outros materiais novos e usados, como laranja, chapéugorro de aniversário, massa de modelar, palitos de churrasco, cartolina e papéis usados, bolas e outras figuras esféricas; tesoura, cola, régua e compasso. Com esses materiais foram trabalhados a construção de todos os sólidos geométricos previstos para serem estudados como também alguns casos de inscrições e circunscrições entre os sólidos. Para complementar as ilustrações das figuras, foram utilizados ainda o datashow para facilitar a visualização de determinadas situações- problema.

A opção metodológica de se trabalhar com a confecção de materiais manipulativos, no caso os sólidos geométricos, ocorreu não devido à dificuldade que os estudantes normalmente possuem em visualizar figuras tridimensionais no plano, pois os estudantes do curso Integrado em Edificações do campus de Aracaju possuem facilidade nessas visualizações. Isso por causa da área de aptidão deles, algumas disciplinas e conteúdo da área técnica que exercitam a capacidade de visualização e imaginação de figuras tridimensionais, mas ocorreu devido à dificuldade do professor em representar no quadro em sala de aula essas figuras. As mesmas acabam sendo construídas de forma distorcida, sem padrão nem proporcionalidade. Tal situação exige dos estudantes uma capacidade de abstração elevada para a compreensão do conteúdo matemático e também a possibilidade metodológica em se discutir e mostrar como materiais podem ser reutilizados para o ensino. Exige-se também como proporcionar a manipulação pelos estudantes dos sólidos geométricos estudados, uma vez que dessa forma, deixa-se de trabalhar apenas com o sentido da visão e utiliza-se também o sentido do tato.

Ao estudar, por exemplo, o cone, os estudantes puderam fazer um corte num chapéu-gorro de aniversário e observar sua planificação lateral, pois ele é formado por um setor circular que pode ser observado com o corte do chapéu-gorro e sua base preenchida com um círculo de papel feito previamente para representá-la. Todos os sólidos estudados teoricamente foram manipulados pelos estudantes através dos materiais solicitados. Através desse processo, foram deduzidas as fórmulas, possibilitando-se que os estudantes fizessem e refizessem a manipulação dos objetos da forma que quisessem. Os estudantes não tiveram que entendê-las apenas no campo da suposição, imaginação e abstração, como ocorre tradicionalmente nas aulas desse conteúdo quando o assunto é desenvolvido, utilizandose apenas o quadro ou a projeção de imagens, através do datashow ou de retroprojetores.

Para evidenciar melhor como ocorreram essas aulas, detalha-se o desenvolvimento da Aula 08: Prismas, que começou com a leitura do texto de Lelis (2013), Prefeitura Municipal de Aracaju trabalha para acabar com o lixo indevidamente depositado nas ruas da cidade. Esse texto deu continuidade à discussão iniciada na aula anterior sobre reciclar, reutilizar e reduzir. Após a leitura do texto, verificamos que os estudantes estavam trazendo informações novas sobre o problema do lixo. Isso mostrou que eles buscaram mais informações desde a última aula. Por isso, foram utilizadas as informações trazidas e eles foram provocados sobre o que achavam de Aracaju produzir tanto lixo. Após alguns minutos de discussão e vários argumentos apresentados, foi lançado o seguinte desafio: Segundo o texto, Aracaju produz aproximadamente 367 toneladas de lixo por dia. Todo esse lixo é coletado por caminhões que possuem uma carroceria em formato de um paralelepípedo de $4 \mathrm{~m}$ de comprimento, por 1,6 $\mathrm{m}$ de largura e 1,5 $\mathrm{m}$ de altura. Determine quantas viagens esses caminhões têm que fazer para recolher todo esse lixo, sabendo que uma tonelada de lixo equivale a um metro cúbico? 
Após alguns minutos, nenhum estudante conseguiu resolver a questão e por isso foram questionados sobre qual era a dificuldade. Eles disseram que não sabiam dizer a capacidade de carga de um caminhão. Foi solicitado para eles pegarem uma caixa de sapato e a régua e questionados sobre como fazer para saber a quantidade que cabe dentro dessa caixa. As respostas começaram a surgir, com um tom de voz de incerteza, mas começaram a dizer que tinha que multiplicar os lados, referindo-se ao comprimento, largura e altura, e foi perguntado o porquê disso. Qual a diferença entre o cálculo de área e o volume? Como fazer para calcular a área de um retângulo? A partir da ideia da área do retângulo que é base vezes altura, foi explicado que, da caixa de sapato, seria base vezes altura, vezes comprimento, pois estava trabalhando com uma figura tridimensional e que a área é trabalhada em figuras bidimensionais. Por isso, sempre é expressa ao quadrado, enquanto que o volume, ao cubo.

A partir dessa discussão, os estudantes calcularam, com a ajuda da calculadora, o volume da caixa de sapatos que tinham em mãos. Esse momento foi aproveitado para mostrar outros prismas que haviam construído sido construídos previamente e questionados sobre quais eram as características comuns entre os prismas construídos. Como poderia definir o que é um prisma? Como poderia classificar os prismas construídos? Os estudantes foram dando respostas a essas perguntas, dizendo que era pelas figuras que formam o prisma, pois um era formado por retângulos, outros por triângulo, quadrados e hexágonos. A partir das diversas respostas, foi possível construir no quadro um resumo de tudo que eles estavam observando e assim, sintetizar as respostas para as três perguntas feitas.

Faltava ainda saber como calcular a área de um prisma e, para isso, foram orientados a recortar cada um dos prismas apresentados na sala, obtendo uma planificação dos mesmos. A partir disso, deduziu-se com os estudantes como seria o cálculo da área de cada um desses prismas, que logo perceberam que era a soma das áreas das figuras planas que formam esses prismas. Após todas essas observações, foi solicitado que resolvessem o problema proposto no início. Após alguns minutos um estudante pediu para ir ao quadro resolver à questão, calculando primeiro a capacidade de carga de um caminhão que era de 9,6 $\mathrm{m}^{3}$ e depois dividindo a quantidade de lixo produzido em um dia pela capacidade de carga de um caminhão, obtendo aproximadamente 38,23 viagens.

Após parabenizar o estudante, este foi questionado sobre o que significa essa resposta encontrada, pois é possível terem ocorrido 38,23 viagens? Os estudantes responderam "não" e disseram que ocorreram 38 ou 39 viagens. A discussão começou no sentido de apontar qual seria a resposta correta. A conclusão deles foi que seria mais lógico terem ocorrido 38 viagens e ficar um caminhão com um pouco de lixo para ser lotado completamente no dia seguinte, o que geraria economia para a empresa. Esse momento foi aproveitado para chamar a atenção sobre a exatidão da Matemática, sua precisão, que em muitos casos, inclusive nesse, necessita de um raciocínio complementar para se chegar à melhor resposta possível, mas como o problema queria saber número total de viagens para levar o lixo, a resposta seria 39 viagens, pois em 38 viagens não seria possível levar todo o lixo.

Para provocá-los ainda mais, foram informados que em Aracaju tinham sido usados, em 2013, vinte e oito caminhões diariamente para recolher o lixo de toda a cidade. Essa coleta foi realizada por uma empresa contratada pela Prefeitura que pagou por esse serviço $\mathrm{R} \$ 60$ milhões de reais. Esses dados despertaram bastante a atenção dos estudantes e, por isso, foi solicitado, como dever de casa, que eles pesquisassem sobre os maiores gastos da Prefeitura de Aracaju e analisassem o que poderia ser feito se ela não tivesse que gastar nada com a coleta de lixo diária.

Como ainda restavam 50 minutos de aula, foi feita a leitura do livro didático referente ao estudo dos prismas, evidenciando a sistematização matemática do conteúdo e trabalhando a resolução de algumas questões propostas no livro. No entanto, os estudantes continuaram fazendo perguntas sobre a coleta de lixo, sobre os aterros sanitários, e principalmente demonstrando muita curiosidade sobre quanto a Prefeitura de Aracaju arrecada por ano e como ela consegue tanto dinheiro assim. A cada questão levantada 
ressaltava-se a importância em procurar mais informações sobre os dados financeiros da Prefeitura, como o prefeito usa esse dinheiro, e que eles conseguiriam facilmente na internet informações sobre os valores arrecadados pela Prefeitura de Aracaju e os gastos realizados.

Essa aula se caracterizou pela dificuldade em sistematizar o conteúdo matemático devido os estudantes não conseguirem focar na aula após a apresentação dos valores gastos pela Prefeitura. Esse problema reflete a falta de informações dos discentes de assuntos ligados diretamente à sua realidade, e como algumas dessas informações impactam imediatamente neles, fazendo-os refletir sobre sua realidade. Mesmo assim, a aula foi finalizada com a resolução de algumas questões percebendo o impacto que as informações trabalhadas trouxeram-lhes.

\section{Aulas de resolução de exercícios}

As aulas de revisão de conteúdo, realizamos uma semana antes da avaliação escrita, destacaram-se por um clima de tensão dos estudantes em saber tudo que iria ser exigido nas provas, bem como constantes pedidos para diminuir o conteúdo a ser cobrado na avaliação. Essas aulas constituíramse em resoluções de questões referente a todo o conteúdo trabalhado no bimestre como uma preparação para a prova seguindo o modelo tradicional de trabalho dos professores de Matemática nas turmas dos cursos integrados.

\section{Aulas de avaliação}

Realizamos quatro avaliações bimestrais, com quatro avaliações de recuperação destinadas aos estudantes que obtiveram notas inferiores a seis, seguindo a metodologia de avaliação padrão dos professores de Matemática para os cursos Integrados.

\section{Considerações Finais}

Ao longo da pesquisa nos questionamos diversas vezes: Quais são as vantagens e desvantagens em trabalhar a Etnomatemática numa perspectiva ambiental? Depois de termos realizado e analisado essas atividades, destacamos os seguintes pontos que ajudam a responder a essa pergunta:
1. Sobreposição de conteúdos: refere-se à situação de se agregar à aula de Matemática outros conteúdos, tanto relativos à Etnomatemática quanto à Educação Ambiental, gerando dificuldade em focar no ensino da Matemática que é o objetivo da aula. No entanto, esse argumento não procede pois o objetivo da aula continuou sendo ensinar o conteúdo de Matemática, e não poderia ser outro numa aula dessa disciplina. Apesar de ter destacado, nos roteiros de ensino das atividades, o conteúdo não só de Matemática, mas também de Etnomatemática e de Educação Ambiental, estes referem-se a conhecimentos utilizados para auxiliar metodologicamente o desenvolvimento do conteúdo de Matemática, ou seja, são conteúdos secundários que emergem da discussão da situação-problema. Eles são fundamentais tanto para contextualizar $\mathrm{o}$ conhecimento matemático como para discutir o conhecimento dos alunos sobre o problema.

O conteúdo da Etnomatemática e da Educação Ambiental, apesar de chamarmos de secundários, não são menos importantes, apenas não são conteúdos trabalhados sistematicamente nas aulas, como o conteúdo matemático, sendo conteúdos fragmentados abordados das duas áreas, utilizados para desenvolver o conteúdo matemático. Não estamos dizendo com isso, que eles não são importantes, muito pelo contrário, enfatizamos apenas que a preocupação de ter mais conteúdos para o professor de Matemática trabalhar não é legítima, pois os conteúdos de Etnomatemática e de Educação Ambiental estão ligados à metodologia da aula e não a inserção de conteúdos curriculares adicionais.

Essa última afirmação é reforçada pela legislação educacional que determina que a Educação Ambiental não se constitua numa disciplina, podendo ser trabalhada como tema transversal no currículo escolar. AEtnomatemática é considerada pelos Parâmetros Curriculares Nacionais também como um tema transversal recomendado para ser trabalhado no ensino da Matemática. Dessa forma, a legislação educacional entende que ambas não são conteúdos adicionais, mas conteúdos a serem explorados metodologicamente nessas aulas.

2. Tempo de duração das aulas: está relacionado a questão anterior no sentido que ao se trabalhar a Educação Ambiental e a Etnomatemática na 
aula de Matemática, acabamos diminuindo o tempo disponível para se ensinar o conteúdo da Matemática. Esse problema é visto pelos professores pessimistas como algo extremamente prejudicial, por terem cada vez menos tempo de ensinar tudo o que considera importante. No entanto, os professores otimistas veem nesse momento a oportunidade de refletir sobre o que realmente é importante ensinar ao aluno e como se pode ensinar. A forma de se entender e encarar esse problema depende do ponto de vista ideológico que a pessoa enxerga.

O que verificamos é que com essa metodologia é possível trabalhar todos os conteúdos previstos dentro do tempo previsto para o Curso, não proporcionando nenhum prejuízo ao conteúdo de Matemática. Sendo assim, esse argumento de que não é possível desenvolver atividades como as realizadas por não haver tempo não é válido. Mas fica a questão: Como isso é possível? A explicação é que o tempo destinado à apresentação e discussão de um problema ambiental não é um assunto a mais a ser trabalhado com os alunos. Esse enfoque constitui-se numa nova forma de introduzir e desenvolver o conteúdo matemático. $\mathrm{Na}$ verdade, não estamos ensinando Educação Ambiental, mas Matemática, a partir da Educação Ambiental. Ou seja, trabalhando apenas um conceito mais amplo de educação.

O mesmo ocorre com a Etnomatemática, pois quando abordamos o conhecimento etnomatemático dos alunos não estamos trabalhando outro assunto, mas trabalhando a Matemática; não apenas a Matemática acadêmica, mas o conhecimento etnomatemático dos alunos. Com isso, ao analisarmos uma questão ambiental a partir dos conhecimentos etnomatemáticos dos alunos, discutimos diversas possibilidades de resolução e interpretação do problema e não apenas uma única através da Matemática acadêmica. Essa questão de tempo para o ensino da Matemática não se constitui, nem se fundamenta num problema em relação ao desenvolvimento dessas atividades.

3. Motivação: possui duas faces, uma de ser obstáculo para o ensino da Matemática, quando o aluno não se interessa pela aula e além de não aprender, gera dificuldades adicionais para o aprendizado dos demais colegas, através de conversas paralelas até ao extremo de se rebelar contra a aula. A outra face aparece quando a motivação é despertada nos alunos e estes proporcionam um ambiente favorável para o desenvolvimento do conteúdo, ou seja, a motivação pode ser a fonte de inúmeros problemas ou gerar um ambiente favorável ao ensino.

É difícil motivar um aluno a determinar o valor do " $x$ " de uma questão que não faz nenhum sentido para ele referente a um conteúdo que o mesmo não entende a importância nem a relevância para sua vida. Não adianta o professor justificar que o conteúdo é necessário e que o estudante vai precisar dele mais à frente, ou que o discente precisará para ingressar em um curso superior. Segundo o Ministério da Educação e Cultura, apenas 30\% dos alunos chegam a iniciar um curso superior, ou seja, de cada 10 alunos que terminam o ensino médio, apenas 3 ingressam em curso superior. Além disso, uma coisa é motivar o aluno a estudar por querer adquirir conhecimento, outra é motivar o aluno por precisar adquirir o conhecimento para conseguir alcançar outro objetivo.

A proposta metodológica de ensinar a Matemática a partir da Etnomatemática pautada na Educação Ambiental Crítica mostrou possuir a seu favor a questão motivacional dos alunos, ao desenvolvermos o conteúdo matemático a partir de problemas que interessam a eles, presentes no cotidiano deles, e discutir, antes de apresentar e desenvolver o conteúdo matemático em si, o conhecimento etnomatemático que eles possuem sobre o problema, evidenciando o conhecimento que eles já possuem, valorizando esses conhecimentos, e mostrando a necessidade de novos para entender e buscar soluções para os problemas de sua realidade.

Observamos, através das atividades de ensino, as seguintes características nos alunos: motivação para assistir a aula de Matemática e a participação nela; interesse em continuar pesquisando mais informações sobre os problemas abordados nas aulas; aumento da autoestima relacionada à capacidade e ao conhecimento que possuem; desenvolvimento de uma forma crítica de entender os problemas de seu cotidiano; desenvolvimento da autonomia e da responsabilidade enquanto cidadãos ativos da 
sociedade. Essas características mostraram que as atividades proporcionaram o desenvolvimento do fator motivacional nos alunos e este contribuiu positivamente para o ensino e aprendizagem na disciplina de Matemática II do $2^{\circ}$ ano Integrado em Edificações.

4. Contextualização: tem uma estreita relação com a motivação. Verificamos que uma forma de conseguir motivarmos os alunos é através da contextualização do ensino à realidade deles. Também, pela utilização dos conhecimentos já adquiridos por eles. Muito já foi discutido sobre esse tema, porque a ideia inicial de contextualizar é colocar em um contexto, e os livros didáticos de Matemática, de modo geral, têm feito isso, mas questionamos: De quem é esse contexto? De que é esse contexto? Para quem é esse contexto? Para que é esse contexto? Essas perguntas deixam esse tema mais complexo, e é nesse cenário que falamos em contextualização, pois só consideramos um ensino contextualizado se responder a essas perguntas.

Observamos que com as atividades de ensino desenvolvidas, conseguimos respondê-las. Por isso, consideramos que trabalhamos um ensino contextualizado a partir de seus conhecimentos etnomatemáticos: De quem é esse contexto? Dos alunos da turma de 2014 do $2^{\circ}$ ano Integrado em Edificações do campus de Aracaju. De que é esse contexto? Da área de interesse deles, a Edificações. Para quem é esse contexto? Para alunos que atuarão como técnicos em Edificações ou que continuarão seus estudos nessa área. Para que é esse contexto? Para ajudá-los e estimulálos a atuar na área de Edificações ou continuar estudando nessa área.

Para conseguirmos responder essas perguntas, inicialmenteidentificamos:osobjetivosdosalunos; seus interesses, inclusive a área de interesse de seus estudos; os conhecimentos etnomatemáticos que possuem; os problemas que vivenciam. A partir de todas essas informações, planejamos as atividades de ensino contextualizadas à realidade deles e desenvolvemos o conteúdo matemático nesse cenário. Isso possibilitou identificarmos qualitativamente as vantagens em trabalhar um ensino contextualizado a partir das falas, gestos, ações, reações e comentários dos alunos, sendo a principal vantagem identificada a motivação deles para estudar.

\section{Referências}

ARAUJO, M. I. O. A dimensão ambiental nos currículos de formação de professores de Biologia. 2004. 209 f. Tese (Doutorado em Educação) Faculdade de Educação, Universidade de São Paulo, São Paulo, 2004.

D'AMBROSIO, U. Etnomatemática: elo entre as tradições e a modernidade. Belo Horizonte: Autêntica, 2001.

FREIRE, P. Educação como prática da liberdade. Rio de Janeiro: Paz e Terra, 1967. . Pedagogia do oprimido. 11. ed. Rio de Janeiro: Paz e Terra, 1994.

\section{LELIS, F. PMA trabalha para acabar com o} lixo indevidamente depositado nas ruas da cidade. Aracaju: [s.n.], 2013. Disponível em: $<$ http://novo.swapi.com.br/index.php?act $=$ leitura\&codigo $=22390>$. Acesso em: nov. 2013.

ORLANDI, E. P. Discurso e texto: formulação e circulação dos sentidos. 3. ed. Campinas: Pontes Editores, 2008.

RICHARDSON, R. J. Pesquisa social: métodos e técnicas. 3. ed. São Paulo: Atlas, 1999.

\section{Sobre os autores:}

Rodrigo Bozi Ferrete - Professor efetivo do Instituto Federal de Sergipe (IFS), lotado na Coordenação do Curso de Licenciatura em Matemática. Professor do Mestrado em Educação Profissional do IFS. Doutor em Educação pela Universidade Federal de Sergipe, Mestre em Educação pela Universidade Federal do Rio Grande do Norte e graduado em Licenciatura em Matemática pela Universidade do Estado do Pará. Atualmente Líder do Grupo de Pesquisa em Inovação Tecnológica do IFS (GPIT). Professor pesquisador com interesse central em pesquisas relacionadas a temática de metodologia de ensino. E-mail: rbferrete@gmail.com

Anne Alilma Silva Souza Ferrete - Possui doutorado em Educação pela Universidade Federal do Rio Grande do Norte (2007), mestrado 
em Educação pela Universidade Federal de Sergipe (2002), graduação em Tecnologia em Processamento de Dados pela Universidade Tiradentes (1994). Atualmente é professora da Universidade Federal de Sergipe lotada no Departamento de Educação (DED), no Centro de Educação e Ciências Humanas (CECH). Professora permanente do Programa de PósGraduação em Educação (PPGED). E-mail: alilma.ferrete50@gmail.com

Cassio Magno de Sousa - Possui ensino médio pelo SESI - Departamento Regional do Estado de Sergipe (2008). Tem experiência na área de Matemática. 